\title{
ANALISIS PEMBELIAN SEPATU SKECHERS DITINJAU DARI PERCEIVED QUALITY, INOVASI PRODUK DAN KELOMPOK REFRENSI DI SOLO SQUARE SOLO
}

\author{
Putri Saptaning Tiar ${ }^{1)}$, Bambang Mursito ${ }^{2)}$, Burhanudin ${ }^{3)}$ \\ ${ }^{1,2,3)}$ Fakultas Ekonomi Universitas Islam Batik Surakarta \\ email : putrisaptaning@gmail.com
}

\begin{abstract}
Abstrak : Penelitian ini bertujuan guna menganalisis pengaruh dari perceived quality, inovasi produk serta kelompok referensi terhadap keputusan konsumen baik secara bersama-sama dan parsial. Populasi penelitian adalah konsumen sepatu Skechers yang dengan sampel sebanyak 100 responden dengan teknik accidental sampling. Analisis yang digunakan adalah regresi linear berganda. Hasil riset menunjukkan bahwa pembelian sepatu Skechers dipengaruhi oleh perceived quality, inovasi produk dan kelompok refrensi baik secara simultan maupun secara parsial. Hasil Adjusted $R^{2}$ sebesar 0,446, berarti pengaruh keputusan pembelian sepatu dipengaruhi oleh perceived quality, inovasi produk dan kelompok referensi adalah 44,6\% dan sebanyak 55,4\% dipengaruhi oleh diluar model misalnya harga, kualitas produk dan citra merek.
\end{abstract}

Kata kunci : perceived quality, inovasi produk, kelompok referensi, keputusan pembelian

\section{PENDAHULUAN}

Industri sepatu mempunyai potensi besar yang dapat berkembang di negara Indonesia. Permintaan sepatu yang terus meningkat di pasar dipengaruhi karena adanya peningkatan daya beli serta berubahnya gaya hidup dari konsumen. Produsen sepatu memproduksi berbagai jenis sepatu baik casual, sport dan slip on. Persaingan yang ketat untuk semua kategori merek dan jenis produk sepatu berupaya untuk memberikan identitas dari pemakainya mulai dari kenyamanan hingga prestise dari pemakainya, hal ini membuat konsumen mempunyai berbagai variasi pilihan sepatu yang sesuai dengan gaya hidupnya. Peranan merek sepatu dapat menjadi faktor yang membedakan antara produk sepatu yang satu dengan sepatu produk lain.

Konsumen memiliki berbagai pilihan untuk memilih sepatu yang diinginkannya, hal ini karena berbagai macam produk dari berbagai merek seperti, Yongki Komaladi, Adidas, New Balance, Nike, Sketchers dan lain sebagainya telah meluncurkan berbagai macam jenis sepatu dengan teknologi, inovasinya. Produsen sepatu mengeluarkan produk agar menarik minat konsumen agar membelinya.

Produsen sepatu Sketchers harus mencari informasi untuk mengembangkan peluang dan memenangkan persaingan dengan pesaingnya agar meningkatkan keputusan konsumen dalam membeli sepatu merek Skechers, Keunggulan bersaing sepatu Skechers yang diproduksi produsen akan mampu menarik konsumen sehingga memutuskan membeli produk sepatu. Mengetahui bagaimana cara konsumen dalam melakukan pembelian menjadi salah satu modal dasar perusahaan dalam memenangkan persaingan sehingga perusahaan harus memahami beberapa hal yang berpengaruh pada keputusan untuk membeli dari konsumen. .

Skechers harus mengetahui keinginan dari konsumen sehingga perusahaan mampu menciptakan produk sepatu yang sesuai dengan keinginan konsumen. Salah satunya adalah perusahaan harus memberikan nilai kualitas (perceived quality) yang lebih baik dibanding pesaingnya. Persepsi kualitas adalah penilaian dari konsumen tentang kualitas produk dengan berdasar pada hal yang diterima konsumen serta keseluruhan harga yang dikeluarkan konsumen agar memperoleh produk tersebut (Najib, dkk, 2016). Saputra dan Semuel (2013) menyatakan bahwa adanya penilaian atas produk merupakan bentuk persepsi dari konsumen, krena itu 
persepsi konsumen pada produk dapat mempengaruhi niat konsumen dalam membeli produk. Riduansyah, dkk, (2016) menyatakan bahwa kesan kualitas yang tinggi akan mempengaruhi keputusan pembelian produk.

Skechers berupaya untuk meningkatkan keputusan pembelian konsumen juga dengan inovasi produk. Rasyid dan Indah (2018) menyatakan bahwa inovasi produk dapat mengurangi rasa jenuh dari konsumen pada pilihan produk yang kurang beragam atau kurang memiliki keunikan tertentu, sehingga dapat mempengaruhi keputusan pembelian konsumen. Timoty, dkk (2018) mengungkapkan bahwa inovasi menjadi bagian perusahaan yang berupaya menggabungkan antara culture perusahaan dengan kemampuan untuk melakukan inovasi untuk memperoleh produk yang sesuai dengan harapan dari konsumen hingga akhirnya konsumen tertarik untuk membelinya.

Kelompok referensi menjadi faktor berpengaruh dalam keputusan dari konsumen dalam membeli produk. Kelompok referensi dapat mempengaruhi ketika konsumen percaya bahwa informasi tentang produk sangat berharga ketika konsumen ingin membeli produk. Kelompok referensi seperti keluarga, saudara dan teman dapat memberikan rekomendasi untuk membeli sepatu merek tertentu ketika mereka sudah menggunakannya dan merasa nyaman atau baik kualitasnya (Setiadi, 2013). Kelompok referensi dapat terdiri dari satu orang atau lebih yang dijadikan sebagai bahan pertimbangan oleh orang lain agar terbentuk sikap bagi konsumen dalam memutuskan membeli produk (Fadilah, 2014).

Beberapa penelitian terdahulu tentang pengaruh persepsi kualitas, inovasi produk dan kelompok rerefensi pernah dilakukan oleh Putri, dkk, (2016) menyatakan bahwa perceived quality berpengaruh pada keputusan pembelian. Umaternate, dkk (2014) menyatakan inovasi berpengaruh pada keputusan pembelian. Ayuningtyas (2016) menunjukkan keputusan pembelian dipengaruhi oleh kelompok referensi.

\section{TINJAUAN TEORI}

1) Pengaruh perceivied quality terhadap keputusan pembelian

Perceived quality adalah hal penting bagi produsen karena apabila produk tidak mampu memberikan kesan kualitas maka produk tersebut kalah dengan produk dari pesaingnya (Tjiptono, 2012: 296). Merek yang memiliki kesan yang kuat maka akan sanggup memperluas diri yang lebih jauh serta memiliki harapan untuk sukses dibanding kesan kualitas dari suatu produk yang lemah (Susanto dan Wijarnako, 2010: 130). Putri, dkk, (2016) dengan hasil penelitiannya bahwa kesan kualitas (perceived quality) berpengaruh terhadap keputusan pembelian.

2) Pengaruh inovasi produk pada keputusan pembelian

Inovasi produk merupakan sebuah pengembangan dari produk atau jasa dan untuk dikenalkan ke pasar guna memenuhi kebutuhan dan keinginan konsumen. Akhiri (2016: 6) dalam penelitiannya menyatakan bahwa inovasi produk mampu menghadirkan harapan pada konsumen sehingga dapat menimbulkan adanya harapan konsumen untuk membeli produk. Umaternate, dkk, (2014) menyatakan bahwa inovasi berpengaruh pada keputusan pembelian.

3) Pengaruh kelompok referensi terhadap keputusan pembelian

Kelompok referensi menjadi unsur penentu dalam keputusan dari konsumen untuk membeli produk. Konsumen biasanya mendengarkan preferensi kelompok referensi mereka karena percaya bahwa informasi yang diberikan tentang produk sangat berharga bagi mereka ketika ingin membeli suatu produk. Setiadi (2013: 121) menyatakan bahwa kelompok referensi digunakan untuk bahan pertimbangan, sehingga dapat membentuk keyakinan, sikap serta pedoman khusus bagi konsumen dalam memutuskan pembelian. Ayuningtyas (2016) 
dalam penelitiannya menunjukkan bahwa kelompok referensi berpengaruh pada keputusan pembelian.

\section{METODE PENELITIAN}

Jenis penelitian ini survei pada pembeli sepatu Skechers dengan pada bulan Maret Agustus 2019. Populasi dalam riset ini adalah pembeli sepatu Skechers di Solo Square Solo. Teknik pengambilan sampel menggunakan accidental sampling dan besarnya sampel adalah 100 konsumen. Pengumpulan data menggunakan kuesioner dengan skala Likert dengan kriteria Sangat Tidak Setuju hingga Sangat Setuju dengan lima alternatif point penilian. Teknik analisis menggunakan regresi linear berganda dnegan kriteria keputusan apabila $p$ value $<0,05$ maka variabel bebas berpengaruh pada variabel terikat.

\section{HASIL DAN PEMBAHASAN}

\section{Identifikasi Konsumen}

Hasil identifikasi responden diketahui responden yang berusia 17-25 tahun (45,0\%), umur 26-35 tahun $(37,0 \%)$ dan > 35 tahun $(18,0 \%)$. Responden yang berpendidikan SD sebanyak $(5,0 \%)$, SMP sebesar $(19,0 \%)$, SMA sebesar $(44,0 \%)$ dan PT sebesar $(32,0 \%)$.

\section{Pengujian Hipotesis}

Pengujian hipotesis ini digunakan untuk mengetahui pengaruh perceived quality, inovasi produk dan kelompok referensi terhadap keputusan pembelian sepatu. Hasil uji hipoetsis dapat dilihat di tabel 1.

Tabel 1. Hasil Uji Hipotesis

\begin{tabular}{lcccc}
\hline \multirow{2}{*}{ Model } & \multicolumn{2}{c}{ Unstandardized Coefficients } & & \\
\cline { 2 - 2 } & $\mathrm{B}$ & $\mathrm{t}$ & \multicolumn{1}{c}{ Sig. } \\
\hline (Constant) & 3.395 & 1.738 & .085 \\
Perceived Quality & .183 & 2.928 & $.004^{*}$ \\
Inovasi Produk & .371 & 5.343 & $.000^{* *}$ \\
Kelompok Referensi & .330 & 5.028 & $.000^{* *}$ \\
\hline Fhitung $=27,578$ & & & .000 \\
Adj R Square $=0,446$ & & & \\
\hline
\end{tabular}

1) Analisis Regresi Linear Berganda

Hasil analisis persamaan regresi linear berganda:

$\mathrm{Y}=3,395+0,183 \mathrm{X}_{1}+0,371 \mathrm{X}_{2}+0,330 \mathrm{X}_{3}+\mathrm{e}$

Nilai koefisien regresi variabel perceived quality $(0,183)$, inovasi produk $(0,371)$ dan kelompok referensi $(0,330)$ sehingga inovasi produk menjadi variabel yang paling dominan di dalam mempengaruhi keputusan konsumen dalam pembelian sepatu Skechers di Solo Square Solo.

2) Koefisien Determinasi

Hasil Adjusted $\mathrm{R}^{2}=0,446$, berarti pengaruh perceived quality, inovasi produk dan kelompok referensi terhadap keputusan pembelian sepatu Skechers adalah 44,6\% dan sisanya sebesar $55,4 \%$ dipengaruhi faktor lain, antara lain adalah harga, citra merek dan kualitas produk. 
3) Uji F

Hasil dari uji $\mathrm{F}$ menunjukkan bahwa nilai $\mathrm{F}_{\text {hitung }} 27,578$ dengan $(p$ value $=0,000)$, maka perceived quality, inovasi produk dan kelompok referensi berpengaruh simultan pada keputusan konsumen dalam membeli sepatu Skechers di Solo Square Solo.

4) Uji t

a. Hasil perhitungan variabel perceived quality diperoleh nilai $t_{\text {hitung }} 2,928$ dan $p$ value $(0,004<0,05)$, maka perceived quality berpengaruh terhadap keputusan konsumen dalam pembelian sepatu Skechers di Solo Square Solo.

b. Hasil perhitungan variabel inovasi produk menghasilkan nilai $\mathrm{t}_{\text {hitung }} 5,343$, dan $p$ value $(0,000<0,05)$, maka inovasi produk berpengaruh terhadap keputusan konsumen dalam pembelian sepatu Skechers di Solo Square Solo.

c. Hasil uji t variabel kelompok referensi sebesar 5,028 serta $p$ value $(0,000<0,05)$, berarti kelompok referensi berpengaruh pada keputusan konsumen dalam pembelian sepatu Skechers di Solo Square Solo.

\section{Pembahasan}

1) Pengaruh perceived quality terhadap keputusan pembelian

Hasil analisis menunjukkan perceived quality berpengaruh terhadap keputusan pembelian dalam pembelian sepatu Skechers di Solo Square Solo. Nilai koefisien regresi bertanda positif sehingga dengan adnaya peningkatan perceived quality produk sepatu maka keputusan pembelian dari konsumen juga semakin meningkat. Hasil ini mendukung penelitain terdahulu dari Putri, dkk (2016) yang menyatakan bahwa perceived quality berpengaruh terhadap keputusan pembelian.

Perceived quality menjadi salah satu faktor yang dipertimbangkan produsen sepatu karena apabila produk sepatu tersebut mampu memberikan kesan kualitas maka produk tersebut akan mampu memenangkan persaingan dengan produk pesaingnya (Tjiptono, 2012: 296). Rangkuti (2014: 192) menyatakan bahwa keputusan pembelian dipengaruhi salah satunya dari persepsi konsumen pada merek produk karena keputusan pembelian didorong oleh perceived quality yang positif. Produk dengan perceived quality yang kuat memiliki kesempatan untuk lebih sukses dibandingkan produk dengan kesan kualitas yang rendah (Susanto dan Wijarnako, 2010: 130).

Hasil pengamatan menunjukkan bahwa sepatu Skechers saat ini menjadi salah satu satu brand kenamaan untuk produk footwear dan dengan statusnya sebagai brand mancanegara maka kualitas menjadi satu keunggulan dari brand sepatu Skechers, dimana konsumen menyatakan bahwa sepatu Skechers nyaman dan berkualitas, sepatunya empuk dan ringan sehingga nyaman dipakai serta memiliki berbagai variasi atau model sepatu sehingga konsumen memiliki beragam pilihan untuk membelinya.

2) Pengaruh inovasi produk terhadap keputusan pembelian sepatu

Hasil perhitungan diperoleh hasil bahwa inovasi produk berpengaruh signifikan terhadap keputusan pembelian dalam pembelian sepatu Skechers di Solo Square Solo. Nilai koefisien regresi bertanda positif sehingga inovasi produk yang semakin baik menyebabkan pembelian produk sepatu juga menjadi meningkat. Hasil ini mendukung penelitian terdahulu dari Umaternate, dkk (2014) menyatakan inovasi mempengaruhi keputusan pembelian konsumen.

Industri sepatu memerlukan inovasi produk yang harus ditawarkan kepada konsumen, karena apabila tidak ada inovasi produk maka perusahaan akan mengalami kebangkrutan, sebaliknya inovasi porduk yang dilakukan perusahaan menyebabkan perusahaan tersebut dapat menjadi pemimpin pasar dengan kreasi, model serta penampilan produk yang inovatif. 
Inovasi produk merupakan kemampuan perusahaan dalam melakukan perubahan pada produk sepatu agar lebih menarik konsumen. Akhiri (2016) menyatakan bahwa inovasi produk dapat berfungsi untuk memberikan harapan bagi konsumen yang ingin membeli sepatu-sepatu dengan model yang baru dan hal tersebut menjadi peluang perusahaan untuk terus melakukan inovasi produk agar konsumen melakukan keputusan pembelian. Implikasi penelitian ini adalah perlunya Skechers menjaga melakukan riset tentang kebutuhan dan keinginan konsumen tentang model dan desain sepatu sehingga Skechers berupaya untuk memenuhi kebutuhan konsumen tentang sepatu tersebut. Hasil pengamatan melalui tanggapan dari konsumen menyatakan bahwa produk-produk sepatu Skechers selalu berkembang, banyak variasi dan desainnya baik untuk sepatu running hingga sepatu-sepatu casual selalu memproduksi model-model baru sehingga menarik minat konsumen untuk melakukan pembelian melalui survei tentang kebutuhan dan keinginan konsumen tentang sepatu,

3) Pengaruh kelompok referensi terhadap keputusan pembelian sepatu

Hasil riset menunjukkan bahwa variabel kelompok referensi memiliki pengaruh pada keputusan pembelian sepatu Skechers di Solo Square Solo. Nilai koefisien regresi adalah positif berarti apabila kelompok referensi menjadi acuan konsumen dalam membeli produk sehingga keputusan dari konsumen untuk membeli sepatu semakin tinggi. Hal tersebut mendukung penelitain terdahulu dari Ayuningtyas (2016) bahwa kelompok referensi memiliki pengaruh pada keputusan pembelian konsumen.

Setiadi (2013: 121) menyatakan bahwa kelompok referensi dapat digunakan sebagai bahan pertimbangan, sehingga dapat digunakan untuk membentuk sikap atau pedoman khusus bagi konsumen untuk memutuskan pembelian. Hal ini karena kelompok referensi atau acuan dalam hal ini adalah teman atau saudara dapat menjadi sumber yang dipercaya tentang detail, jenis, model dan ku alitas produk ketika ingin membeli produk sepatu. Sumarwan (2011: 136) menyatakan bahwa sikap dalam sebuah kelompok memiliki pengaruh yang lebih besar bila dibandingkan pada kelompok yang memiliki pengaruh lemah. Konsumen lebih cenderung terpengaruh pada kelompok referensi apabila informasi yang diberikan dianggap valid dan relevan terhadap permasalahan yang dihadapi apabila sumber informasi tersebut dapat dipercaya. Produsen Skechers perlu melalukan upaya dalam meningkatkan keputusan pembelian sepatu Skechers melalui kelompok referensi adalah produsen memberikan detail tentang kelebihan-kelebihan sepatu baik tentang kenyamanan, kualitas, keringanan untuk lebih meningkatkan kenyamanan konsumen dalam melakukan pembelian sepatu. Hasil pengamatan menunjukkan bahwa konsumen tertarik membeli sepatu Skechers karena beberapa temannya sudah menggunakannya dan mereferensikan untuk menggunakan sepatu Skechers karena nyaman dan ringan saat dipakai.

\section{KESIMPULAN}

Kesimpulan penelitian ini adalah bahwa pembelian sepatu Skechers dipengaruhi oleh perceived quality, inovasi produk dan kelompok referensi. Berdasarkan hasil tersebut maka produsen sepatu Skechers perlu menjaga dan meningkatkan kualitas produknya agar konsumen semakin puas dalam membeli sepatu sehingga dapat merekomendasikan ke orang lain bahwa sepatu Skecher mempunyai kualitas yang baik serta karyawan hendaknya bersikap ramah terhadap semua konsumen dan mampu memberikan penjelasan tentang berbagai informasi sepatu yang dijual sehingga konsumen berupaya untuk melakukan pembelian. 


\section{DAFTAR PUSTAKA}

Hawin Anam Fadhlullah, HA., Arifin, R dan Hufron, M. 2018. "Pengaruh Gaya Hidup, Pengetahuan Konsumen dan Kelompok Acuan terhadap Keputusan Pembelian Kendaraan Mitsubishi di PT. Sun Star Motor Kediri”. e - Jurnal Riset Manajemen Prodi Manajemen. Fakultas Ekonomi Unisma.

Najib, MA, Soesanto, H dan Sukresna, IM. 2016. “Analisis Pengaruh Brand Awareness, dan Perceived Value terhadap Keputusan Pembelian (Studi Pada Konsumen Produk Deterjen Merek BOOM di Kabupaten Bojonegoro)". Jurnal Sains Pemasaran Indonesia. Vol 15 No 1, hal 62-73.

Rasyid, HA dan Indah, AT. 2018. "Pengaruh Inovasi Produk dan Harga Terhadap Keputusan Pembelian Sepeda Motor Yamaha di Kota Tangerang Selatan". Perspektif. Vol. XVI No. 1, hal. 39-49.

Saputra, R dan Samuel, H., 2013. "Analisa Pengaruh Motivasi, Persepsi, Sikap Konsumen Terhadap Keputusan Pembelian Mobil Daihatsu Xenia di Sidoarjo". Jurnal Strategi Pemasaran. Vol 1 No 1, hal 1-12.

Timoty, H.Y., Mandey, SL., Ogi, I..W.J. 2018. Pengaruh Harga, Merchandise dan Inovasi Produk terhadap Keputusan Pembelian Dump Truck 6 Roda di PT. Astra International Isuzu Cabang Manado. Jurnal EMBA. Vol. 6 No.2, Hal. 838 - 847 